\title{
Juan Roa como metáfora e ironía de la identidad colombiana en El crimen del siglo, de Miguel Torres. ${ }^{24}$
}

\section{Juan Roa as metaphor and irony of Colombian identity in El crimen del siglo, by Miguel Torres.}

\author{
Olga Lucía Ruiz Echeverri
}

Recibido: 1 de Agosto 2011. Aprobado: 15 de Septiembre 2011

\begin{abstract}
Resumen
Este artículo se aproxima a la novela El crimen del siglo escrita por Miguel Torres desde el concepto "marco de referencia" para mostrar cómo se configura Juan Roa en metáfora e ironía de la identidad nacional. Hacer al magnicida el personaje principal de la obra, y no a Gaitán, le permiten subvertir el orden, pues el crimen del siglo es el de Roa Sierra, linchado por la turba enfurecida, con lo que construye un "doble sentido" irónico. Se plantea El crimen del siglo como metáfora de la historia de Colombia, que desde el año 48 vive la impotencia para salir del delirio colectivo yendo y viniendo entre la adoración a los saqueadores y la lucha contra el saqueo.
\end{abstract}

Palabras clave: El crimen del siglo; Miguel Torres; Marco de referencia; Jorge Eliécer Gaitán; Novela colombiana.

\begin{abstract}
This paper addresses El crimen del siglo novel written by Miguel Torres from the term "framework" to show how Juan Roa is set to metaphor and irony of national identity. Ask magnicida the main character of the novel, not Gaitán, allow you to subvert the order, as the crime of the century is that of Roa Sierra, lynched by the angry mob, which constructs a "double meaning" ironic. El crimen del siglo is seen as a metaphor for the history of Colombia, which since 48 lives impotence to leave the collective delirium shuttling between the worship of the looters and the fight against looting.
\end{abstract}

Keywords: El crimen del siglo; Miguel Torres; Framework; Jorge Eliécer Gaitán; Colombian novel.

El crimen del siglo, novela del hombre de letras y de teatro Miguel Torres, convoca "marcos de referencia" (Harshaw 1997) ${ }^{25}$ que corresponden a un hito de la historia colombiana: el asesinato de Jorge Eliécer Gaitán, líder político liberal que se perfilaba como seguro ganador de las elecciones presidenciales, en el contexto de un país en guerra

\footnotetext{
${ }^{24}$ Artículo avance de la tesis de Maestría en Literaturas colombiana y latinoamericana de la Escuela de Estudios Literarios de la Universidad del Valle.

${ }^{25}$ Los conceptos de marco de Referencia, Campo de Referencia Interno y Campo de Referencia externo, se toman de Benjamín Harshaw en. Ficcionalidad y campos de referencia. (1997)
}

Poligramas 36, segundo semestre 2011, ISSN 0120-4130. 
bajo el régimen conservador y durante la IX Conferencia Panamericana, suceso éste de trascendencia continental que le daba una atmósfera especial a la vida bogotana por esos días. $^{26}$

Aún hoy el magnicidio de Jorge Eliécer Gaitán ofrece más incógnitas que respuestas. La multitud que linchó a Juan Roa Sierra -culpado en la escena del crimen como autor material -, en gesto acusatorio arrastró su cadáver al palacio presidencial, señalando así al presidente Ospina Pérez y al partido conservador como autores intelectuales del asesinato del caudillo liberal. La novela subvierte la tradición historiográfica y en lugar de centrarse en la víctima, Gaitán el gran personaje histórico, tiene como protagonista al supuesto victimario. Sigue paso a paso las miserias de Roa Sierra, el personaje más enigmático de esta historia y tan lleno de secretos como el crimen mismo.

El autor parte de las pocas declaraciones que dieron los familiares de Juan Roa en el interrogatorio policial, donde quedó claro que su misma familia sabía muy poco de él. Las escasas referencias al inculpado y mucha investigación histórica y literaria, son los puntos de partida de la narración, que se encarga de inventar un personaje homónimo; porque el de la literatura, así se llame igual, es una ficción que se levanta sobre datos, fechas y calles que existieron en los años cuarenta y que son el esqueleto sólido de este Roa de papel que termina por ser el único Roa existente, como se puede observar en la lectura de las críticas sobre la novela, que asumen frecuentemente al ser de ficción que habita con nosotros como si fuera el que dejó este mundo el 9 de abril de 1948.

Mapas de Bogotá, anteriores y posteriores a la época de los hechos históricos, sirvieron de base al escritor para edificar prolijamente su Bogotá de ficción como un espejismo de la Bogotá de entonces. Allí se construye el tiempo de la novela, que no va más allá de la vida del personaje. Comienza la mañana del día de su muerte y termina cuando ésta ya se ha cumplido, poco después de la una de la tarde. Pero mientras pasan las horas entre el último desgarrador intento de escapar a su destino y la consumación del mismo, el narrador nos lleva por la vida de Roa, detallando minuciosamente su último año, sobre todo las últimas semanas. Así, un personaje de trazos débiles en la vida real, se dibuja

\footnotetext{
${ }^{26}$ En esta Conferencia, mientras países como Brasil, Argentina, Chile y Guatemala, entre otros, estimaban de primer orden la definición de un Plan Marshall al estilo europeo para América Latina y consideraban la relación con el mundo comunista asunto interno de cada país, el General Marshall tenía la agenda contraria: firmar una declaración anticomunista y hacer oídos sordos a las demandas económicas latinoamericanas. El asesinato de Gaitán fue utilizado hábilmente para concretar la agenda del General y nació la OEA con la declaración anticomunista de sus miembros.
} 
en la novela con fuerza de luces y sombras; toma plena vida como personaje de ficción y se erige como imagen del colombiano de futuro incierto de aquella época y de esta, que es la nuestra y la del autor.

Cada calle, cada fecha, las manifestaciones de las Antorchas y del Silencio, los anuncios publicitarios, las canciones que suenan en los cafés y en la radio, las películas que se anuncian en las marquesinas de los teatros, contribuyen a cimentar la ilusión de realidad; se desdoblan en la ficción en otros semejantes y distintos que existen por la necesidad del relato, que están para llevarnos por los intersticios del personaje central, cuyo nombre coincide con el del supuesto asesino de Gaitán.

¿Quién es Roa en El crimen del siglo? Un personaje con fuertes conflictos de identidad que se ve a sí mismo como Gonzalo Jiménez de Quesada, el conquistador español que fundó Bogotá y fracasó en la empresa de encontrar El Dorado, o como el general Santander, héroe de la independencia. Ambos son sombras, máscaras donde Roa vierte su frágil identidad: como Jiménez de Quesada, vive el ansia de encontrar un gran tesoro, bultos de oro, y es liberal como el General Santander, considerado por la tradición historiográfica el fundador del Partido Liberal, partido de Gaitán, de Roa y de toda su familia. Pero Jiménez de Quesada y Santander están en orillas distintas. El primero es conquistador, invasor de estas tierras y el segundo es prócer de la independencia de España, la invasora; en este sentido aluden a la confrontación interna de Roa Sierra y a la confrontación histórica de esta tierra.

La identidad de Roa es tan frágil, que ni siquiera se puede definir en relación con un oficio porque es “todero@, es decir, sin profesión; no tiene certeza de su futuro, no sabe a dónde lo llevarán sus pasos y es el quirólogo Johan Umland Gert quien se encarga de darle esperanzas y se convierte en su guía espiritual, en una imagen del padre; con él se identifica Roa cuando le sugiere que traduzca su nombre y se llame Juan, como él. Según las observaciones del alemán, Roa Sierra es un ser huraño, reservado, inestable, inseguro, de rasgos psicológicos complejos, de mirada esquiva, cuerpo rígido a la defensiva, pero tono y palabras respetuosas; el análisis de su caligrafía muestra un personaje elemental, corto de espíritu, de personalidad apocada y medrosa, pero obstinada. Umland se propone disuadirlo de creer que es la reencarnación del general Santander y fortalecer su autoestima. Juan por su parte se da las mañas para consultar gratis y obtener -además-,

Poligramas 36, segundo semestre 2011, ISSN 0120-4130. 
pequeñas sumas de dinero en sus visitas; préstamos impagables como los que le hace su madre.

Roa siempre está buscando algo, escapando de algo. Y fracasa, fracasa siempre. En el primer capítulo, la novela nos muestra su último pedido de auxilio a Johan Umland Gert buscando escapar de su destino homicida, pero su potencial salvador no le cree: Usted no es capaz de matar una mosca, Juan, como si no lo conociera. ¿De dónde sacó semejante disparate? Piense lo que quiera, profesor, replicó Roa Sierra, pero vine a decírselo para que trate de impedirlo" (Torres, 2006, p. 14).

El rol de verdugo de Gaitán no es compatible con el Roa pusilánime que Umland Gert conoce y en cambio coincide perfectamente con la cara fantasiosa de este personaje que la semana anterior le había hablado de un viaje maravilloso de donde regresaría con diez mulas cargadas de oro.

Como El crimen del siglo se refiere a hechos que sucedieron en la historia nacional, sabemos que el personaje morirá el mismo 9 de abril, tras el asesinato de Gaitán. Sin embargo la novela se narra de tal manera, que mantiene la tensión dramática; lleva al lector a desear con vehemencia que el personaje pueda escapar a su destino y por momentos parece que lo va a lograr, porque diestramente el autor nos conduce por las que Brecht denomina alternativas muertas ${ }^{27}$ como si se fueran a efectuar.

Juan se ve involucrado en dos conspiraciones simultáneamente: en la de los escoltas de Gaitán y en la que participan Urrutia y Tom. Mientras los escoltas de Gaitán lo obligan a conseguir el arma de la operación criminal, Roa es contratado para ser chofer en la otra conspiración, oculta a sus ojos pero clara para los lectores; intuimos que allí su vida estaría más protegida y si esta operación concluyera antes que la otra, Roa se salvaría. Pero un remezón en la cúpula deja a Juan fuera del juego y al parecer retrasa la operación. Entonces no le queda sino la opción de conseguir el arma, que es una tarea casi imposible; cada que lo va a lograr, surge un nuevo obstáculo y pareciera que Juan Roa Sierra, en contra de lo que sabemos por el marco de referencia histórico, fuera a eludir el destino de magnicida; pocas horas antes de la primera cita para el crimen, Roa

\footnotetext{
${ }^{27}$ Brecht plantea que cuando un personaje asume una alternativa, por ejemplo Romeo decide beber el veneno, quedan muchas otras alternativas muertas que el actor deberá dejar traslucir. Romeo podría: llevarse el cadáver de su amada, tener un accidente y romper el frasco del veneno, siéndole imposible beberlo o morir de otra manera; además el fraile podría llegar a tiempo, etc. Brecht también denomina este procedimiento no, sino (no sucede esto, sino aquello). El efecto en el espectador es que $v e$ las alternativas muertas.
} 
no tiene todavía un arma y cuando finalmente la obtiene, resulta ser un viejo revólver con una sola bala.

El móvil inicial de Juan para asesinar a Gaitán es un impulso vengativo porque el político no se compadeció de su situación económica; este impulso se transforma luego en proyecto más o menos delirante, posteriormente como ya se dijo, se le atraviesa como alternativa de trabajo ser chofer de un auto en una conspiración que involucra a Urrutia, donde no tendría el rol de asesino, sino de cómplice (aunque él no lo sabe); finalmente el crimen se convierte en su obligación y condena. El marco de referencia "asesinato de Gaitán” existe en la novela en íntima relación con el drama de Juan Roa, pero también ella se encarga de crear móviles más amplios, en la situación socio política del país:

La siguiente fue otra semana de convulsiva turbulencia en Colombia. La escalada de terror siguió en ascenso. La amenaza de defender a sangre y fuego la posición de Ospina Pérez, lanzada meses atrás en el Senado de la República, (...) cobraba vigencia día, a día como consigna de arrase, abanderada por el gobierno para legitimar con el poder de la fuerza sus debilidades políticas. A pesar de (...) las exigencias políticas de Gaitán en demanda de medidas efectivas para poner fin al desbordamiento oficial, los sabotajes, los incendios y las masacres de campesinos liberales no daban tregua (Torres. 2006. p. 160)

La obra también pone a circular otras conspiraciones y relata someramente sus móviles pero solo se detiene en aquellas que hablen de Roa, como la conspiración en la que participan Urrutia y Tom, que da cuenta del desespero de Juan: "Yo le jalo a lo que sea, doctor $(. .$.$) ¿Y a qué sueldo aspiras, chino? Al que me ofrezcan, doctor, y en lo primero$ que salga, por la plata baila el perro" (Torres. 2006. p. 121).

El Campo de Referencia externo es muy amplio, no se limita a la historiografía, los mapas de Bogotá y documentos periodísticos de la década del cuarenta, sino que abarca marcos de referencia de orden estético, retórico, político, en fin de todos los órdenes de la vida humana que requiere la construcción ficcional, porque ella es la que convoca ese Campo; en ella la voluntad de existir del texto termina por imponerse incluso a la voluntad del autor. A propósito dice Miguel Torres ${ }^{28}$ que cuando comenzó la escritura de El crimen del siglo estaba convencido de que Juan Roa era el asesino, pero a medida que la escritura avanzaba y se configuraba el personaje, resultaba cada vez más dudosa su culpabilidad. Esto determinó: que en la escena del crimen coincidan personajes de varias

\footnotetext{
${ }^{28}$ Entrevista de la autora a Miguel Torres. Bogotá de 5 de Abril de 2012
} 
conspiraciones $^{29}$, que otra arma que se levante primero que la de Juan Roa y que el narrador no atribuya a un arma específica ninguno de los tres disparos.

Si nos detenemos en el título de la obra, El crimen del siglo alude por una parte -en el nivel manifiesto-, a un marco de referencia que es de conocimiento público: el asesinato de Jorge Eliécer Gaitán a mediados del siglo XX; pero el título también juega con $E l$ Siglo, diario progubernamental de entonces, en la orilla opuesta a Gaitán y sugiere que en el crimen hubo compromiso de los sectores políticos vinculados a este periódico. Sin embargo, como la novela nos conduce por los laberintos de la vida insustancial de Roa Sierra, personaje central de la obra, el crimen del siglo es ante todo el crimen que cometen en la persona de Juan Roa los conspiradores que lo ponen como carne de cañón y la turba que lo lincha.

Aunque el Juan de la novela no es en ningún momento el Juan de la historia, alude a él y en este sentido, como ya se dijo, la novela subvierte el orden: el crimen del siglo no es el del personaje político importante, sino el del presunto asesino, un personaje marginal que metafóricamente es imagen de esa misma multitud desesperanzada que lo mata a pedacitos. En este juego de sentidos el título es una ironía donde el plano manifiesto alude al gran personaje histórico pero el plano del contenido latente (como diría Freud), delata por lo menos a dos fuerzas asesinas pertenecientes a clases sociales opuestas: los personajes de hablar pausado y don de mando que no salen de las sombras sino que hacen de Juan la extensión de su mano asesina y la multitud ciega de ira.

Siguiendo este orden de ideas, la novela presenta una serie de acciones de gran ironía, como el hecho de que el protagonista sea un personaje nimio y no el gran personaje histórico; que el asesino de Gaitán haya sido gaitanista; que justamente cuando Juan abandona su intención de matar al caudillo, por una Trampa del azar termine involucrado en un plan para matarlo; que el único proyecto que logre culminar sea precisamente aquel que lo conduce a su aniquilación final. Igualmente es irónico que en el primer capítulo Johan Umland Gert, el quiromántico, el conocedor del alma humana y de las intimidades de Juan Roa, no le crea cuando éste le confiesa que va a matar a Gaitán ese mismo día. Al final de la novela nos daremos cuenta de que en el preciso momento en que Roa le va

\footnotetext{
${ }^{29}$ El Mandamás de la conspiración de los escoltas, un hombre elegantísimo, Tom y el moreno, Brancov, entre otros. 
a demostrar a Umland la veracidad de su información sacando el arma, llega la visitante que el alemán ha estado esperando, circunstancia que lo impide.

En la secuencia titulada Sombras en las tinieblas, este hombre que ya no quiere asesinar a Gaitán debe hacer enormes esfuerzos para conseguir el arma homicida; la acción contradice al deseo y Juan se convierte en personaje trágico que no puede esquivar su destino: sabe que si mata a Gaitán arriesga su vida; si no lo mata, morirá también y lo que es peor, morirán su mujer y su hija. Aquí la ironía se da por la oposición y doble sentido de la acción: se observa en el nivel manifiesto que Juan busca afanosamente el arma y en esa misma acción están latentes sus temores y el deseo de escapar de ese compromiso. El "doble sentido" irónico permite que esta secuencia trágica adquiera un tono farsesco, aunque padezcamos con el personaje la angustia de actuar a contrapelo de la voluntad, así anhelemos la aparición de un Deus ex machina que resuelva la situación, la ironía nos permite estar involucrados con el personaje y a la vez tomar distancia y comprender su situación. Como se ampliará más adelante, El crimen del siglo como totalidad, es metáfora de la Colombia presente y del siglo pasado, pero es metáfora cruzada por la ironía, según se acaba de señalar.

¿Qué se cuenta con la historia de Roa? se cuenta la zozobra de un desempleado que vive en el marasmo llevado por la angustia del fracaso, de la dependencia económica y afectiva. En ese mundo nos sumerge la novela, en el mundo de un joven lleno de frustraciones y sufrimientos en un país bañado en sangre, de un hombre de ese pueblo desesperado que sigue al líder carismático que aparece como única esperanza. Juan se aferra a su madre, a Umland, a Gaitán, a la promesa del Dr. Urrutia, al presidente, al regalo del Mohán, a cualquier quimera que prometa sacarlo del abismo. No sabe cómo solucionar su vida: los préstamos impagables no le sirven sino para resolver su día a día miserable y anodino, espera el milagro de un tesoro, se embarca en empresas inciertas que no le garantizan mucho; anhela una solución repentina, (tan incrustada en el imaginario nacional y en las nuevas generaciones de sicarios y narcos).

El estado esquizofrénico de no saber a ciencia cierta quién es, si conquistador español o héroe de la independencia, o chofer de taxi o vigilante -porque su identidad es volátil-, lleva a este hijo del pueblo a involucrarse en una de las conspiraciones que se tejieron contra Gaitán. Su fantasía de venganza, nacida de la rabia contra el líder admirado que no

Poligramas 36, segundo semestre 2011, ISSN 0120-4130. 
le consiguió trabajo, termina volviéndose más que deseo cumplido, obligación perentoria justo cuando ha renunciado a tal despropósito. La búsqueda delirante de identidad que se mueve del conquistador al prócer, es síntoma que busca por el camino tortuoso una salida; es su actividad de mayor autonomía y es censurada y reprimida; no le queda sino la espera pasiva de soluciones externas o milagrosas.

El crimen del siglo es una metáfora de Colombia, más precisamente, la imagen de nuestra historia; hablando del año 48 habla de presente siglo XXI, de la impotencia histórica para salir del delirio colectivo que vivimos los colombianos yendo y viniendo de la adoración a los saqueadores, al deseo de luchar contra el saqueo; porque lo que se diga de Roa, se dice también del pueblo colombiano que, como el personaje de la novela, tiene identidad incierta y termina construyendo activamente el destino que no quiere. Como la turba bogotana que tras la muerte de su líder, solo fue rabia, frustración y destrucción en el Bogotazo.

Mientras las versiones oficiales sobre el asesinato real de Gaitán han ocultado por decenios las circunstancias del crimen, la novela inventa una versión del asesinato a través de la vida nimia del posible homicida, pero no satisface el deseo colectivo de descubrir el crimen, sino que muestra el carácter huidizo e ilusorio de tal deseo, como diría Iser (1997). En este contexto, Roa Sierra, aunque es un personaje marginal, adquiere dimensiones históricas en la novela, se convierte en imagen del colombiano sin futuro que pierde, o puede estar en riesgo de perder, lo poco que le queda de dignidad, identidad y bienes.

Siguiendo a Iser (1997) podríamos decir que la reconstrucción de los años cuarenta en Colombia en la novela de Torres, oculta y a la vez muestra el drama de más de cinco décadas de guerra, desplazamiento forzado y constreñimiento de la población, signada por sucesivas ilusiones y desesperanzas. Pero no lo hace en abstracto, sino que lo encarna en un personaje, Juan Roa, que es a la vez personaje singular y plural. Su singularidad nos permite ver el drama como algo único, propio del universo de Juan Roa, que anhela nostálgico la compañía de María, la mujer de su vida y para esto necesita un trabajo; pero cada paso que da, lo lleva al desastre.

La pluralidad de Juan permite que nos veamos más o menos completos en ese mundo. Roa Sierra resulta un personaje familiar para nosotros, los lectores; lo vemos en otros

Poligramas 36, segundo semestre 2011, ISSN 0120-4130. 
jóvenes sicarios actuales y desde allí el Gaitán histórico se nos transforma en máscara de muchos otros muertos. La historia del 48 se vuelve metáfora de la historia actual y sin embargo, no deja de hablar de los acontecimientos que sacudían nuestro país en esa época, encarnados en el drama de Juan, un hombre que vive en borrador, de identidad precaria, ignorante, pobre, solitario, desempleado y sin futuro.

\section{Bibliografía}

Harshaw, Benjamín, (1997) Teorías de la ficción literaria. Ficcionalidad y campos de referencia. Arco Libros.

Iser, Wolfang. (1997) La ficcionalización: dimensión antropológica de las ficciones literarias. Teorías de la ficción literaria. Arco Libros.

Torres, Miguel. (2006) El crimen del siglo. Seix barral. Biblioteca Breve. 